\title{
A IMPORTÂNCIA DA ATUAÇÃO DO PSICÓLOGO NOS CASOS ENVOLVENDO VIOLÊNCIA DOMÉSTICA E FAMILIAR CONTRA A MULHER
}

THE IMPORTANCE OF PSYCHOLOGIST PERFORMANCE IN CASES INVOLVING DOMESTIC AND FAMILY VIOLENCE AGAINST WOMEN

\begin{abstract}
Dhaianny Oliveira Camargos Acadêmica do $10^{\circ}$ período do Curso de Psicologia, Faculdade Alfa Unipac de Teófilo Otoni, e-mail: dhaicamargos@gmail.com

Mayanne Hollerbach Amaral Acadêmica do $10^{\circ}$ período do Curso de Psicologia, Faculdade Alfa Unipac de Teófilo Otoni, e-mail: mayannehollerbach@outlook.com

Isabel Corrêa Pacheco Docente e Especialista em Psicologia Hospitalar, Faculdade Alfa Unipac de Teófilo Otoni, e-mail: bel.correa.to@gmail.com
\end{abstract}

Recebido: 20/05/20201- Aceito: 20/05/2021 
Revista Multidisciplinar do Nordeste Mineiro, v.2 2021/02

ISSN 2178-6925

TEÓFILO OTONI - MG

2020 


\section{A IMPORTÂNCIA DA ATUAÇÃO DO PSICÓLOGO NOS CASOS ENVOLVENDO VIOLÊNCIA DOMÉSTICA E FAMILIAR CONTRA A MULHER}

Trabalho de Conclusão de Curso apresentado à Faculdade Alfa Unipac de Teófilo Otoni como requisito parcial para a obtenção do Título de Bacharel em Psicologia.

Orientadora: Prof. ${ }^{\text {a }}$ Isabel Corrêa Pacheco 


\section{Resumo}

Em virtude da grande quantidade existente de casos de violência doméstica e familiar contra a mulher, tal circunstância tem sido amplamente discutida por estudiosos das mais diversas áreas. No campo da psicologia, são averiguadas as consequências psicoemocionais provocadas por esse ato cada vez mais corriqueiro nas vítimas, visto que o mesmo pode acarretar várias condições, como: estresse pós-traumático, ansiedade, síndrome do pânico e comportamentos autodestrutivos. Assim, o presente artigo científico visa discorrer sobre a importância da atuação do psicólogo nos casos de violência doméstica e familiar contra a mulher, buscando analisar como é o acompanhamento da psicologia frente ao sofrimento dessas pessoas. A opção pelo referido objeto de estudo está ligada ao fato da violência doméstica e familiar contra a mulher se tratar de uma situação de saúde pública, atingindo duramente a integridade física e psicológica das vítimas, sendo fundamental verificar a relevância do atendimento prestado pela figura do psicólogo perante esses casos. Quanto aos procedimentos metodológicos e técnicos, o respectivo trabalho fundamenta-se no método de abordagem qualitativa, sendo que a técnica de pesquisa vincula-se à revisão bibliográfica. Por fim, foi possível concluir que a atuação do psicólogo perante às vítimas desse tipo de violência é essencial, uma vez que o mesmo possui a função de reduzir o sofrimento vivenciado por essas pessoas, procurando recuperar a autoestima, independência e personalidade, bem como buscando uma melhor qualidade de vida para essas pessoas.

Palavras-chave: Violência Doméstica; Violência Familiar; Consequências Psicoemocionais; Atuação do Psicólogo. 


\section{Abstract}

Due to the large number of cases of domestic and family violence against women, this circumstance has been widely discussed by scholars from the most diverse areas. In the field of psychology, the psycho-emotional consequences caused by this increasingly common act in victims are investigated, as it can lead to various conditions, such as: post-traumatic stress, anxiety, panic syndrome and selfdestructive behaviors. Therefore, this scientific article aims to discuss about the importance of the psychologist's performance in cases of domestic and family violence against women, seeking to analyze how psychology is monitored in the face of these people's suffering. The choice for the referred object of study is linked to the fact that domestic and family violence against women is a public health situation, affecting the physical and psychological integrity of the victims, it is essential to check the relevance of the care provided by the psychologist before these cases. As for the methodological and technical procedures, the respective work is based on the qualitative approach method, and the research technique is linked to the literature review. Finally, it was possible to conclude that the psychologist's performance before the victims of this type of violence is essential, since it has the function of reducing the suffering experienced by these people, trying to recover their self-esteem, independence and personality, as well as seeking to provide them with a better quality of life.

Keywords: Domestic and Family Violence; Psycho-emotional Consequences; Psychologist's Performance.

\section{Introdução}

A violência doméstica e familiar contra a mulher tem sido um assunto amplamente discutido por inúmeras ciências, haja vista ser um fenômeno social que vem ganhando cada vez mais visibilidade no Brasil e no mundo. Certamente, tal circunstância se trata de um problema complexo, sendo que seu enfrentamento requer a composição de serviços de naturezas diversas, exigindo grande dedicação de trabalho em rede (LIMA, 2020).

Dentre esses serviços, encontra-se o prestado pelo psicólogo, uma vez que em um caso de violência doméstica e familiar, a vítima é acometida por diversas consequências de caráter psicoemocionais, tais como, estresse pós-traumático, ansiedade, síndrome do pânico, comportamentos autodestrutivos, entre outros (AMICUCCI, 2017).

Diante da respectiva abordagem, é possível levantar a seguinte problemática: qual seria a importância e o papel do psicólogo no atendimento às mulheres vítimas de violência doméstica e familiar? 
Sendo assim, vislumbra-se como objetivo geral analisar como é o acompanhamento da psicologia frente ao sofrimento das mulheres vítimas da referida forma de violência.

Por outro lado, tem-se como objetivos específicos descrever o contexto histórico da Lei no 11.340/2006, conhecida como Lei Maria da Penha; pormenorizar a violência doméstica e familiar; levantar dados estatísticos sobre a violência contra a mulher; e investigar o papel do psicólogo no atendimento às vítimas de violência doméstica e familiar.

Ressalta-se que a opção pelo objeto de estudo em questão pode ser justificada pela grande quantidade de casos envolvendo violência doméstica e familiar contra mulher no Brasil, sendo considerada uma situação de saúde pública, atingindo duramente a integridade física e psicológica das vítimas. Dessa forma, se torna fundamental verificar a magnitude do atendimento prestado pela figura do psicólogo perante esses casos.

\section{Metodologia}

Com relação à metodologia de abordagem teórica da presente pesquisa, a mesma se encontra fundamentada através do método de interpretação dedutiva, partindo-se do geral para o especifico, possuindo como finalidade explicar o conteúdo da premissa levantada.

Por sua vez, no tocante às técnicas de pesquisa utilizadas para a coleta e análise dos dados, tem-se como base a revisão bibliográfica, objetivando-se a sustentação da pesquisa científica para, consequentemente, chegar-se a uma determinada conclusão acerca do objeto de estudo alçado.

Os critérios de inclusão para as obras foram: estar disponível na íntegra, estar disponível em língua portuguesa, ter sido publicadas de 2010 até a presente data, exceto as publicações clássicas sobre o tema, como é o caso da Constituição Federal de 1988 (BRASIL, 1988), da Lei no 11.340/2006 (BRASIL, 2006) e do Relatório no 54/2001 da Comissão Interamericana de Direitos Humanos (CIDH, 2001).

Ademais, com relação às pesquisas lançadas no Google Acadêmico, utilizouse de inúmeros descritores, tais como: "violência doméstica e estatísticas"; "violência doméstica e saúde pública"; "violência doméstica e psicologia". 


\section{Revisão da literatura}

\subsection{Contexto histórico da Lei no 11.340/2006 - Lei Maria da Penha}

Antes de tudo, é imprescindível destacar que com o advento da Constituição Federal de 1988, passou a ser consagrada a igualdade entre homens e mulheres, conforme disposto no artigo $5^{\circ}$, inciso I, do mais importante diploma legal do ordenamento jurídico brasileiro:

Art. 5o Todos são iguais perante a lei, sem distinção de qualquer natureza, garantindo-se aos brasileiros e aos estrangeiros residentes no País a inviolabilidade do direito à vida, à liberdade, à igualdade, à segurança e à propriedade, nos termos seguintes:

I - homens e mulheres são iguais em direitos e obrigações, nos termos desta Constituição (BRASIL, 1988).

Assim, o referido dispositivo assegura que todos são iguais perante a lei, não havendo distinções que qualquer natureza; sendo que homens e mulheres possuem os mesmos direitos e obrigações.

Por outro lado, também é necessário mencionar que sempre houve um verdadeiro abismo entre a previsão constitucional e a árdua realidade social encarada pelas mulheres. Em outras palavras, mesmo com a promulgação da Lei Maior, a luta pelo fim da violência doméstica e familiar continuou a ser algo preocupante e recorrente na sociedade brasileira, especialmente no seio familiar, sendo indispensável o empenho do Poder Legislativo para a criação de um diploma legal que viesse a coibir e punir tal prática, visto que esse tipo de violência deixa estigmas na mulher e em seus dependentes menores (BRASIL, 2015).

Diante disso, o Poder Legislativo buscou promover comandos infraconstitucionais voltados para a valorização da mulher, com o objetivo de protegela dos preconceitos sofridos no dia a dia, bem como do sentimento de inferioridade. Entre esses comandos, encontra-se a Lei no 11.340/2006, também conhecida como "Lei Maria da Penha", responsável por estabelecer mecanismos para erradicar a prática da violência doméstica e familiar (LIMA, 2020).

Por esse ângulo, Valéria Diez Scarance Fernandes contextualiza: 
Penha, farmacêutica, era casada com um professor universitário. Após anos de violência doméstica, foi vítima de duas tentativas de homicídio praticadas por seu marido e ficou paraplégica em 1983. Houve dois julgamentos pelo Tribunal do Júri, mas o agressor de Maria da Penha somente foi preso em 2002 e cumpriu dois anos de pena (FERNANDES, 2015, p. 16).

O respectivo diploma legal recebeu tal denominação em decorrência da situação fatídica ocorrida com Maria da Penha Maia Fernandes, a qual sofreu diversas agressões desferidas por seu marido, inclusive duas tentativas de homicídio, vindo a ficar paraplégica, enquanto seu agressor não sofreu uma sanção penal justa, cumprindo somente dois anos de pena.

Em decorrência da repercussão negativa do acontecimento, foi formalizada denúncia perante a Comissão Interamericana de Direitos Humanos, resultando na condenação do Brasil ao pagamento de indenização no valor de 20 mil dólares à vítima, bem como a recomendação da adoção de medidas voltadas para a simplificação da tramitação processual, conforme consta no Relatório no 54/2001 da referida entidade (CIDH, 2001).

A Lei Maria da Penha inovou ao romper o tradicional processo penal, criando um processo provido de efetividade social, com o objetivo de proteger a mulher e prevenir a violência doméstica no âmbito doméstico e familiar. De outra maneira, o processo por essa forma de violência passou a ser constituído multidisciplinarmente, modificando e renovando, com o intuito de romper com o ciclo de violência doméstica e familiar (FERNANDES, 2015).

A Lei Maria da Penha dispõe acerca da criação dos Juizados de Violência Doméstica e Familiar contra a Mulher, determinando medidas de proteção e assistência às vítimas de agressão em situação de violência doméstica e familiar, nos termos do artigo $1^{\circ}$ do mencionado diploma legal (BRASIL, 2006).

Por esse ângulo, Alice Bianchini faz o seguinte posicionamento:

[...] a Lei Maria da Penha deu um tratamento totalmente diferenciado ao conflito, na medida em que criou os Juizados de Violência Doméstica e Familiar contra a Mulher, com todo um aparato preventivo e assistencial à vítima e ao agressor (como também aos familiares e às testemunhas). Por conta disso, a atuação dos Juizados deve diferir daquela tradicionalmente legada à justiça criminal, não se limitando à apreciação das responsabilidades criminais e à distribuição de castigo (BIANCHINI, 2016, p. 118). 
Indubitavelmente, a Lei Maria da Penha, caiu no gosto da sociedade, propagando-se de maneira considerável e, por consequência, chamando a atenção para o alarmante problema da violência doméstica e familiar, cada vez mais comum nos ambientes familiares brasileiros, possuindo como objetivo a prevenção e punição da violência de gênero no ambiente doméstico e familiar.

\title{
3.2 A violência doméstica e familiar
}

A violência se tornou um fenômeno social cada vez mais comum, atingindo populações tanto no âmbito local quanto global, no público e no privado, estando sua definição em frequente modificação, haja vista que inúmeras práticas e comportamentos passaram a ser classificados como formas de violência.

Nesse sentido, Valéria Diez Scarance Fernandes afirma que:

\begin{abstract}
A conceituação de violência está sujeita a transformações sociais, culturais, históricas e jurídicas. Condutas que eram consideradas legítimas sofreram modificações ao longo dos tempos e hoje são rotuladas de atos violadores. [...] Nos dias atuais, a cultura da violência está associada ao caráter masculino, daí por que as mulheres figuram em regra como vítimas e não causadoras de violência nas relações afetivas (FERNANDES, 2015, p. 4748).
\end{abstract}

Dessa forma, atualmente a violência a denominada cultura da violência está vinculada à natureza masculina, razão pela qual na grande maioria das vezes as mulheres figuram como vítimas de violência nas relações afetivas.

Nas sociedades em que a conceituação do gênero feminino geralmente é associada ao âmbito familiar e à maternidade, o aspecto fundamental da estruturação social do gênero masculino é seu desempenho no âmbito público, sendo o provedor e protetor da família. Há de se destacar que, atualmente, nessas mesmas sociedades, a mulher se encontra presente na força de trabalho e, por conseguinte, no mundo público, sendo alvo de diversas e constantes discriminações e violências (JESUS, 2015).

Ao tratar da violência doméstica e familiar contra a mulher, a Lei Maria da Penha, em seu artigo 5ํㅡ e incisos, define tal circunstância da seguinte forma: 
morte, lesão, sofrimento físico, sexual ou psicológico e dano moral ou patrimonial:

I - no âmbito da unidade doméstica, compreendida como o espaço de convívio permanente de pessoas, com ou sem vínculo familiar, inclusive as esporadicamente agregadas;

II - no âmbito da família, compreendida como a comunidade formada por indivíduos que são ou se consideram aparentados, unidos por laços naturais, por afinidade ou por vontade expressa;

III - em qualquer relação íntima de afeto, na qual o agressor conviva ou tenha convivido com a ofendida, independentemente de coabitação. Parágrafo único. As relações pessoais enunciadas neste artigo independem de orientação sexual (BRASIL, 2006).

Logo, a violência doméstica e familiar contra a mulher pode ser conceituada juridicamente como qualquer ação ou omissão fundada no gênero, causando sofrimento físico, sexual, psicológico, moral, e na pior das hipóteses, lesão ou morte. Além disso, destaca-se que esse tipo de violência pode ocorrer no âmbito da unidade domiciliar, da família, ou em qualquer relação íntima de afeto.

De outra sorte, o parágrafo único do artigo $5^{\circ}$ da Lei $n^{0}$ 11.340/2006 estabelece que as relações pessoais elencadas pelo mencionado dispositivo independem da orientação sexual dos envolvidos (BRASIL, 2006).

Cumpre destacar que a distinta proteção conferida pela Lei Maria da Penha ao gênero feminino somente incide quando a violência praticada contra a mulher ocorrer no âmbito doméstico, familiar, ou ainda, em qualquer relação íntima de afeto. Logo, de maneira oposta, caso a mulher seja vítima de determinada violência que não se enquadre nessas circunstâncias, afigura-se indevida a aplicação do aludido diploma legal (LIMA, 2020).

Dessa forma, rompendo com os padrões no Direito brasileiro, a Lei $\mathrm{n}^{\circ}$ 11.340/2006 utilizou a expressão "violência" como uma violação ao direito inerente à mulher. Ou seja, a tradicional diferenciação entre "ameaça" e "violência" passa a inexistir quando se tratar de violência doméstica e familiar (FERNANDES, 2015).

Por sua vez, o artigo $7^{\circ}$, incisos I a V, do referido diploma legal, apresenta as seguintes formas de violência doméstica e familiar contra a mulher: a) violência física; b) violência psicológica; c) violência sexual; d) violência patrimonial; e e) violência moral (BRASIL, 2006).

A violência física pode ser definida como toda ofensa à integridade física e corporal cometida através do emprego de força, abrangendo empurrões, arremesso de objetos, tapas, socos, pontapés, queimaduras, entre outras agressões, com a 
finalidade de ofender a integridade ou saúde corporal da vítima, deixando ou não hematomas (BIANCHINI, 2016).

A violência psicológica é conceituada como qualquer comportamento que provoque dano emocional e redução da autoestima ou que prejudique e dificulte o pleno desenvolvimento, ou que objetive degradar ou controlar as ações, comportamentos, convicções e vontades da vítima, por intermédio de ameaça, constrangimento, depreciação, manipulação, isolamento, vigilância constante, entre outros formas que lhe cause prejuízo à saúde psicológica (BRASIL, 2006).

A violência sexual, compreendida corno qualquer comportamento que constranja a vítima a presenciar, a manter ou a participar de relação sexual contra a sua vontade, através de intimidação, ameaça, coibição ou emprego da força; que a impulsione a comercializar ou a fazer uso da sua sexualidade, que a impossibilite de utilizar qualquer meio contraceptivo ou que a obrigue ao matrimônio, à gravidez, ao aborto ou à prostituição, por meio de coerção, extorsão, suborno ou manipulação; ou que defina limites ou suprima o exercício de seus direitos sexuais e reprodutivos (BRASIL, 2006).

A violência patrimonial pode ser definida como qualquer conduta que caracterize a contenção, subtração, o desmantelamento parcial ou total dos seus objetos da vítima, assim como ferramentas de trabalho, documentos pessoais, bens, valores e direitos ou recursos econômicos (BRASIL, 2006).

A violência moral, entendida como qualquer comportamento que impute falsamente à vítima fato considerado como crime, fato ofensivo à sua reputação ou ofensa à sua dignidade ou decoro (LIMA, 2020).

Por fim, é importante mencionar que, conforme o próprio artigo $7^{\circ}$, caput, da Lei Maria da Penha estabelece, o rol por ele elencado não é taxativo, sendo perfeitamente possível o reconhecimento de outras formas de violência doméstica e familiar contra a mulher.

\subsection{Um breve cenário da violência contra a mulher no Brasil}

Conforme mencionado, com o advento da Lei $n^{0}$ 11.340/2006, a violência doméstica e familiar praticada contra as mulheres tem ganhado ampla visibilidade no Brasil, sendo estabelecidos mecanismos de proteção à mulher apoiada em políticas públicas específicas, em uma concepção tanto preventiva como assistencial à vítima, 
mas, também, de responsabilização do agressor. Com relação a este fenômeno, Damásio de Jesus afirma:

\begin{abstract}
A violência contra as mulheres é um dos fenômenos sociais mais denunciados e que mais ganharam visibilidade nas últimas décadas em todo o mundo. Devido ao seu caráter devastador sobre a saúde e a cidadania das mulheres, políticas públicas passaram a ser buscadas pelos mais diversos setores da sociedade, particularmente pelo movimento feminista. Trata-se de um problema complexo, e seu enfrentamento necessita da composição de serviços de naturezas diversas, demandando grande esforço de trabalho em rede. A integração entre os serviços existentes dirigidos ao problema, entretanto, é difícil e pouco conhecida (JESUS, 2015, p. 8).
\end{abstract}

Atualmente, a violência contra as mulheres é um dos acontecimentos mais discutidos nas mais variadas áreas, demonstrando ser uma questão de caráter multidisciplinar, visto se tratar de um problema extremamente complexo.

Ademais, a violência contra a mulher ocorre nos mais variados ambientes, pouco importando qual seja a classe social, etnia, idade, assim como pode ocorrer nas mais diversas relações pessoais. Assim, é possível concluir que a violência contra a mulher é compreendida como um fenômeno de natureza social fundamentado nas desigualdades de gênero e não como uma mera consequência da pobreza ou alcoolismo e drogas, como parte da sociedade costuma acreditar atualmente (BRASIL, 2015).

Embora a tendência é de que a violência doméstica e familiar possua como vítimas mulheres de menor poder aquisitivo, a própria situação vivenciada por Maria da Penha demonstra como uma mulher vinda de uma família abastada, com nível superior de escolaridade também pode sofrer com a violência no âmbito doméstico e familiar (JESUS, 2015).

Além disso, é importante mencionar que a mulher também pode figurar como sujeito ativo nos casos de violência doméstica e familiar. Isto significa que a Lei Maria da Penha não exclui do seu campo de proteção a prática dessa forma de violência em relações de natureza homoafetiva entre mulheres, haja vista que uma mulher também pode perfeitamente ser agredida por outra no âmbito doméstico e familiar (BRASIL, 2015).

Em pesquisa realizada pelo Instituto de Pesquisa DataSenado, em parceria com o Observatório da Mulher contra a Violência, o percentual de entrevistadas que declararam ter sofrido algum tipo de violência doméstica ou familiar provocada por um 
homem se manteve relativamente constante de 2005 a 2015, sofrendo uma considerável alta em 2017:

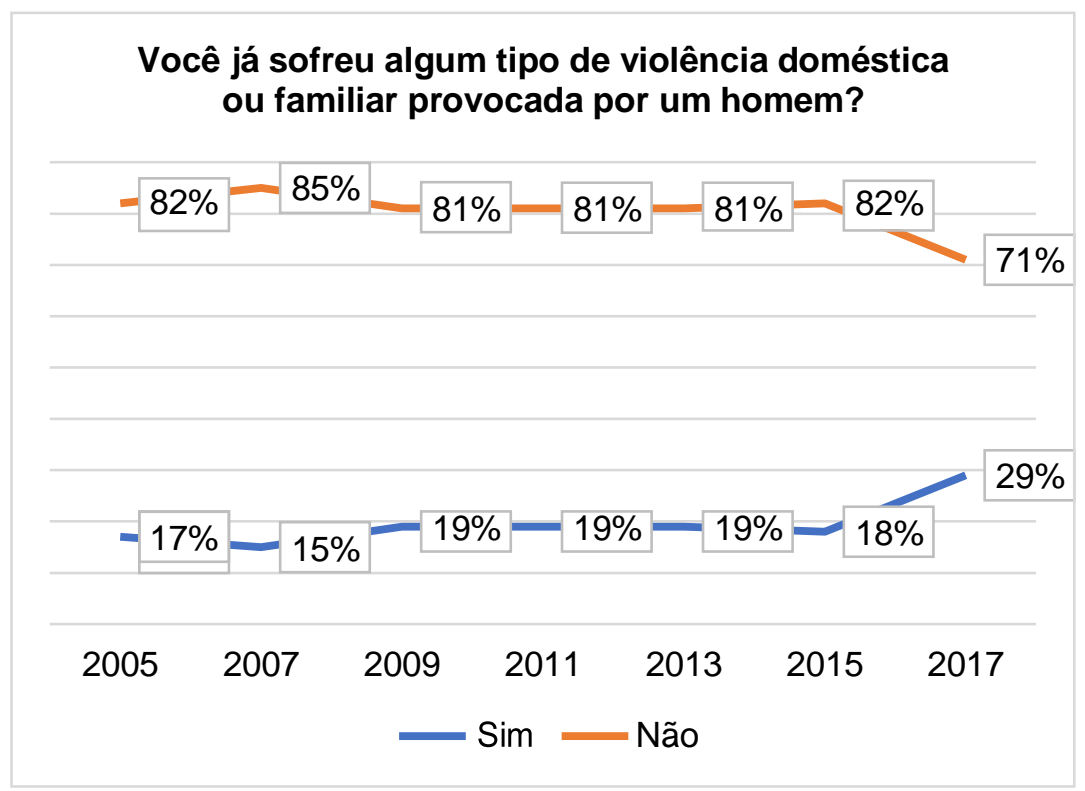

Fonte: Instituto de Pesquisa DataSenado, 2017.

Observa-se que o índice de entrevistadas que relataram sofrer violência doméstica ou familiar consiste em um número abaixo do esperado. Isso ocorre pelo fato de muitas mulheres sentirem vergonha em declararem acerca das agressões sofridas, optando por omitir tal situação (FERNANDES, 2015).

Nesse contexto, Damásio de Jesus afirma:

Os dados são desencontrados e nem sempre atualizados. Especialistas concordam que eles são geralmente subestimados, urna vez que há urna espécie de "pacto de silencio", pelo qual as mulheres vítimas da violência não denunciam, e algumas vezes até mesmo protegem e escondem seus agressores (JESUS, 2015, p. 14-15).

Desse modo, os dados estatísticos levantados, embora apresentem números consideráveis, ainda assim nem sempre há uma atualização dessas informações, que além de tudo é ampliada pela falta de denúncia, sendo que em determinados momentos até mesmo defendem seus próprios agressores.

No que diz respeito às formas de violência elencadas no artigo $7^{\circ}$ da Lei $n^{\circ}$ 11.340/2006, o Instituto de Pesquisa DataSenado, em parceria com o Observatório da Mulher contra a Violência, levantou os seguintes dados referentes ao ano de 2017, 
levando em consideração que em determinados casos as entrevistadas sofreram mais de um tipo de violência doméstica ou familiar:

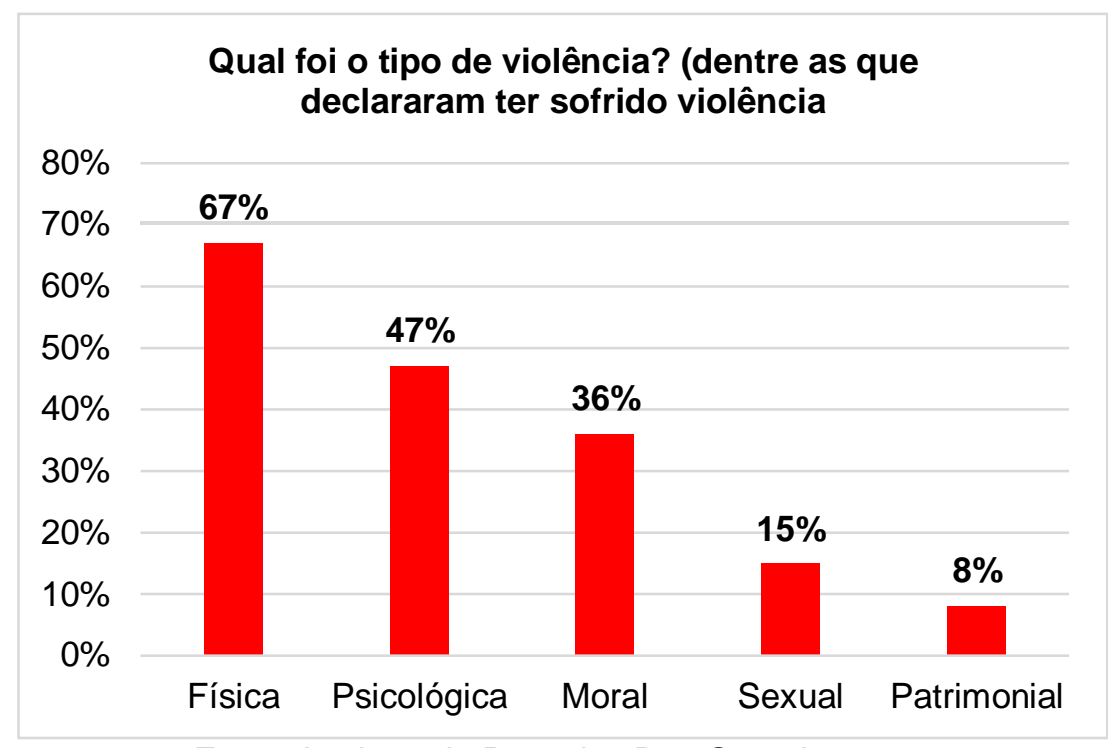

Fonte: Instituto de Pesquisa DataSenado, 2017.

Por outro lado, registra-se que no âmbito internacional, o Brasil ocupa a $5^{\text {a }}$ posição no ranking mundial de violência contra a mulher, possuindo uma taxa de impressionantes 4,8 homicídios por 100 mil mulheres. Somente El Salvador, Colômbia, Guatemala e Rússia taxas de homicídios superiores à do Brasil (WAISELFISZ, 2015).

Diante dos dados apresentados, é possível notar um índice alarmante de violência no cenário doméstico e familiar brasileiro, envolvendo agressões físicas, psíquicas, morais, sexuais e patrimoniais, que, na pior das hipóteses, acabam resultando em mortes.

\subsection{O papel do psicólogo no atendimento às vítimas de violência doméstica e familiar}

Conforme explanado anteriormente, a violência doméstica e familiar contra a mulher se manifesta através de inúmeras formas, tais como a violência física e a violência psicológica, deixando estigmas consideráveis na estrutura emocional da ofendida. Logo, é essencial a realização de uma abordagem acerca da importância e do papel do psicólogo no atendimento às vítimas de violência doméstica e familiar. 
No entanto, ressalta-se que, preliminarmente, é indispensável tecer breves ponderações sobre as consequências psicológicas causadas por esse tipo de violência à vítima.

De acordo com a Organização Pan-americana de Saúde - OPAS, a violência doméstica e familiar contra a mulher é reconhecida como uma questão de saúde pública, que atinge negativamente as integridades física e psíquica da ofendida, bem como sua percepção de segurança (OPAS, 2017).

Nesse sentido, Silvana Rodrigues Mota e Osvaldo Piedade Pereira da Silva aduzem:

A violência doméstica deixa marcas profundas e muitas vezes inesquecíveis. A mulher que sofre vários tipos de violência ao mesmo tempo, acaba por adquirir sintomas e até mesmo doenças de cunho físico e psicológico, devido às agressões (MOTA; SILVA, 2019, p. 109).

Portanto, a violência doméstica e familiar prejudica a mulher, uma vez que provoca graves consequências de ordem psicológica que podem importuná-la por toda a vida. Como exemplos, é possível citar distúrbios alimentares e do sono, consumo de álcool e drogas psicotrópicas, fobias, depressão, dentre outras (ALBUQUERQUE, 2019).

Por esse ângulo, Ana Caroline Ferreira Bonetto Amicucci assevera:

\begin{abstract}
Dentre os sintomas psicológicos encontrados nas vítimas de violência doméstica que podemos mencionar são: insônia, agitações, desatenção, irritabilidade, falta de apetite, e até o aparecimento de sérios problemas mentais como a depressão, ansiedade, síndrome do pânico, estresse póstraumático, além de comportamentos autodestrutivos como tentativas de suicídio. A mulher desenvolve sentimento de insegurança, a sua vida ocorrendo alterações psíquicas que surgem em função do trauma, juntamente ao estado de choque que é imediato após a agressão, sobretudo a sua autoestima (AMICUCCI, 2017, s.p.).
\end{abstract}

Assim, consequentemente, as vítimas acabam por desenvolver sentimento de insegurança, decorrente das alterações de natureza psicológica provenientes do abalo, simultaneamente ao estado de choque, surgindo imediatamente após as agressões, impactando diretamente sua autoestima.

Em razão da violência doméstica e familiar ser visualizada como um problema de caráter multidisciplinar, existe a necessidade de uma cordial colaboração entre profissionais de áreas distintas, com incumbências diferenciadas. Sob a perspectiva 
de um imbróglio jurídico e terapêutico, é preciso que todos os profissionais envolvidos possuam conhecimento sobre questões criminais em proteção da mulher, bem como acerca das questões psicológicas (DIAS, 2019).

Para a compreensão dos estigmas psicoemocionais da vítima desse tipo de violência, torna-se essencial um olhar aprofundado, buscando aqueles sentimentos que foram alvejados pelo comportamento violento do agressor, seja ele físico ou psicológico (MOTA; SILVA, 2019).

À vista disso, sendo a saúde psicológica da ofendida transgredida, é sempre importante a presença de acompanhamento psicológico, com o objetivo de observar o estado psicoemocional da vítima, haja vista o forte abalo emocional causado por esse tipo de conduta, razão pela qual é indispensável o acompanhamento e tratamento com profissionais provenientes da psicologia (LOBO, 2016).

Diante disso, Samira Mafioletti Macarini e Karla Paris Miranda asseveram:

O psicólogo, independente da área em que esteja atuando, é um dos profissionais que contribui para a promoção dos Direitos Humanos, relacionando-se com as áreas da saúde, educação, social, privada, políticas públicas e demais áreas. Quando se trata da atuação deste profissional na realidade das mulheres em situação de violência conjugal, a relação com as políticas públicas é quase que obrigatória, constituindo um diálogo entre o Estado e a sociedade, para atender os direitos fundamentais dos envolvidos (MACARINI; MIRANDA, 2018, s.p.).

Em vista disso, o psicólogo, pouco importando qual seja o seu campo de atuação, colabora para o progresso dos direitos humanos fundamentais, possuindo contato com inúmeras áreas, tais como, saúde e políticas públicas. Aliás, ressalta-se que as políticas públicas são instrumentos primordiais, uma vez que promovem o diálogo entre o Estado e a sociedade, com o propósito de efetivar esses direitos inerentes à pessoa humana.

Também é importante salientar que o Centro de Referência de Assistência Social - CRAS e o Núcleo de Apoio a Saúde da Família - NASF atuam como espaços de apoio dentro da rede assistencial voltada para os casos envolvendo violência doméstica e familiar contra a mulher, prestando serviços especializados e exclusivos de atendimento à mulher, possuindo expertise na presente questão (GROSSI; et al., 2015).

Destaca-se que no atendimento, o psicólogo deve estabelecer uma ligação terapêutica com a vítima, primordial para a confiabilidade e o trabalho de intervenção, 
oferecendo toda a assistência e acolhimento necessário. Em seguida, o profissional deve buscar a redução do sofrimento emocional, contribuindo para uma melhor qualidade de vida da ofendida e, aos poucos, resgatar sua autoestima, independência e personalidade (SIMIANO; D'ÁVILA, 2017).

Aliás, é importante salientar que o psicólogo pode prestar um atendimento tanto no âmbito clínico quanto grupal, uma vez que por intermédio dessas atuações, temse a finalidade de desempenhar uma satisfatória receptividade e escuta, com o propósito de reduzir o momento difícil em que as vítimas se encontram e prestar suporte psicológico para seguirem uma nova vida (PIOVEZAN; MONTEIRO, 2015).

Conforme Bruna Adames, Simoni Urnau Bonfíglio e Ana Paula Sesti Becker:

[...] o acolhimento psicológico proporciona ao acolhido(a) um outro olhar de si mesmo(a) quanto à situação que vivencia, ou seja, não se focaliza somente 0 ato de violência, mas sim as repercussões deste na vida integrada do sujeito, em seus diferentes aspectos, como o histórico familiar, cultura, crenças, valores, escolaridade, entre outros (ADAMES; BONFÍGLIO; BECKER, 2018, s.p.).

Dessa forma, verifica-se que o apoio psicológico exercido por um profissional qualificado é primordial não apenas para fortalecer as vítimas de violência doméstica e familiar que colocam fim a um ciclo de violência, mas, também, para incentivar aquelas que, muitas vezes pelo medo, não são capazes de enfrentar relacionamentos abusivos.

\section{Considerações finais}

A presente pesquisa teve como finalidade abordar a importância da atuação do psicólogo nos casos de violência doméstica e familiar contra a mulher, buscando analisar como é o acompanhamento da psicologia frente ao sofrimento dessas pessoas.

Ressalta-se que no tocante ao objetivo geral e objetivos específicos, ambos foram alcançados, visto que restou demonstrada como é a atuação da psicologia diante das vítimas de violência doméstica e familiar.

Ante tudo o que foi exposto no decorrer do desenvolvimento, observa-se que as mulheres alcançaram grandes conquistas inerentes à sua proteção, principalmente quanto à violência doméstica e familiar, pois no contexto histórico, existia um grande 
abismo entre a mulher e homem. Somente após o advento da Constituição Federal de 1988 e da Lei Maria da Penha é que ambos passaram a ter os mesmos direitos e obrigações.

No entanto, mesmo com esse acolhimento legal, existe uma grande quantidade de casos registrados em que as vítimas sofrem violências de cunho físico, psicológico, moral, sexual e patrimonial.

Em razão dessas experiências indesejáveis, muitas vezes as vítimas acabam desenvolvendo inúmeros problemas de natureza psicoemocional, que vão desde um episódio de ansiedade até a depressão, consequentemente, podendo resultar em suicídio.

Por conseguinte, é imprescindível a intervenção do psicólogo nos casos envolvendo violência doméstica e familiar contra a mulher, visto que tal profissional buscará firmar um vínculo terapêutico com as vítimas, oferecendo todo o suporte e acolhimento individual e grupal necessário.

Logo, pode-se concluir que a atuação do psicólogo perante às vítimas desse tipo de violência é essencial, uma vez que o mesmo possui a função de reduzir o sofrimento vivenciado por essas pessoas, procurando recuperar a autoestima, independência e personalidade, bem como buscando proporcionar-lhes uma melhor qualidade de vida.

\section{Referências}

ADAMES, Bruna; BONFÍGLIO, Simoni Urnau; BECKER, Ana Paula Sesti. Acolhimento psicológico para mulheres vítimas de violência conjugal. Scielo, 2018. Disponível em: http://pepsic.bvsalud.org/scielo.php?script=sci arttext\&pid=S180989082018000200012\&lng=pt\&nrm=iso. Acesso em: 07 nov. 2020.

ALBUQUERQUE, Neimar de Figueiredo. Violência doméstica e familiar: o impacto na relação com a Lei Maria da Penha. DireitoNet, 2019. Disponível em: https://www.direitonet.com.br/artigos/exibir/11306/Violencia-domestica-e-familiar-oimpacto-na-relacao-com-a-Lei-Maria-da-Penha. Acesso em: 05 nov. 2020.

AMICUCCI, Ana Caroline Ferreira Bonetto. Violência doméstica e familiar, a silenciosa consequência psicológica na vítima. Conteúdo Jurídico, 2017. Disponível em: https://conteudojuridico.com.br/consulta/Artigos/50229/violenciadomestica-e-familiar-a-silenciosa-consequencia-psicologica-na-vitima. Acesso em: 06 nov. 2020. 
BIANCHINI, Alice. Lei Maria da Penha: Lei n. 11.340/2006: aspectos assistenciais, protetivos e criminais da violência de gênero. 3. ed. São Paulo: Saraiva, 2016.

BRASIL. [Constituição (1988)]. Constituição da República Federativa do Brasil de 1988. Disponível em:

http://www.planalto.gov.br/ccivil 03/constituicao/constituicao.htm. Acesso em: 01 nov. 2020.

. Lei $\mathrm{n}$-11.340, de 7 de agosto de 2006. Cria mecanismos para coibir a violência doméstica e familiar contra a mulher, nos termos do § 8 do art. 226 da Constituição Federal [...]. Disponível em:

http://www.planalto.gov.br/ccivil 03/ ato2004-2006/2006/lei/l11340.htm. Acesso em: 01 nov. 2020.

Senado Federal. Instituto de Pesquisa DataSenado. Violência doméstica e familiar contra a mulher. Senado Federal, 2017. Disponível em:

https://www12.senado.leg.br/institucional/datasenado/arquivos/aumenta-numero-demulheres-que-declaram-ter-sofrido-violencia. Acesso em: 03 nov. 2020.

Senado Federal. Lei Maria da Penha: perguntas e respostas: em favor da vida, pelo fim da impunidade. Brasília, 2015. Disponível em:

https://www12.senado.leg.br/institucional/procuradoria/proc-publicacoes/cartilha-leimaria-da-penha-perguntas-e-respostas. Acesso em: 01 nov. 2020.

COMISSÃO INTERAMERICANA DE DIREITOS HUMANOS - CIDH. Relatório n 54, de 4 de abril de 2001. Caso 12.051, Maria da Penha Maia Fernandes. Disponível em: http://www.sbdp.org.br/arquivos/material/299 Relat\%20n.pdf. Acesso em: 01 nov. 2020.

DIAS, Maria Berenice. A Lei Maria da Penha na Justiça. 6. ed. Salvador: Juspodivm, 2019.

FERNANDES, Valéria Diez Scarance. Lei Maria da Penha: o processo penal no caminho da efetividade: abordagem jurídica e multidisciplinar. São Paulo: Atlas, 2015.

GROSSI, Patricia Krieger; et al. 0 atendimento especializado às mulheres em situação de violência no âmbito da rede suas: uma demanda invisibilizada. VII Jornada Internacional Políticas Públicas, 2015. Disponível em:

https://repositorio.pucrs.br/dspace/bitstream/10923/8155/2/O Atendimento Especiali zado as Mulheres em Situacao de Violencia no ambito da rede SUAS uma d emanda invisibilizada.pdf. Acesso em: 12 nov. 2020.

JESUS, Damásio de. Violência contra a mulher: aspectos criminais da Lei $\mathbf{n}$. 11.340/2006. 2. ed. São Paulo: Saraiva, 2015.

LIMA, Renato Brasileiro de. Legislação criminal especial comentada. 8. ed.

Salvador: Juspodivm, 2020. 
LOBO, Hewdy. Quais as consequências psicológicas da violência doméstica contra a mulher?. Jusbrasil, 2016. Disponível em:

https://lobo.jusbrasil.com.br/artigos/348787434/quais-as-consequenciaspsicologicas-da-violencia-domestica-contra-a-mulher. Acesso em: 06 nov. 2020.

MACARINI, Samira Mafioletti; MIRANDA, Karla Paris. Atuação da psicologia no âmbito da violência conjugal em uma delegacia de atendimento à mulher.

Scielo, 2018. Disponível em:

http://pepsic.bvsalud.org/scielo.php?script=sci arttext\&pid=S1679-

494X2018000100013. Acesso em: 06 nov. 2020.

MOTA, Silvana Rodrigues; SILVA, Oswaldo Piedade Pereira da. Violência doméstica e suas consequências psicoemocionais. Revista Eletrônica Casa de Makunaima, Edição 3, Vol. 2 - № 3, Jan./Jun. 2019. Disponível em: https://periodicos.uerr.edu.br/index.php/casa de makunaima/article/view/387. Acesso em: 05 nov. 2020.

ORGANIZAÇÃO PAN-AMERICADA DA SAÚDE - OPAS. Folha informativa violência contra as mulheres. 2017. Disponível em:

https://www.paho.org/bra/index.php?option=com content\&view=article\&id=5669:folh a-informativa-violencia-contra-as-mulheres\&ltemid=820. Acesso em: 05 nov. 2020.

PIOVEZAN, Bianca Aparecida; MONTEIRO, Carla Fernanda Barbosa. Intervenções do profissional do psicólogo do suas no atendimento à mulheres vítimas de violência doméstica: uma revisão dos últimos 10 anos. Revista UNINGÁ, Vol.24, n.1, out./dez. 2015. Disponível em:

https://www.mastereditora.com.br/periodico/20151006 132936.pdf. Acesso em: 07 nov. 2020.

SIMIANO, Rafaela; D'ÁVILA, Luciane da Silva. O papel do psicólogo no atendimento a mulheres vítimas de violência doméstica. 2017. Disponível em: http://www.uniedu.sed.sc.gov.br/index.php/pos-graduacao/trabalhos-de-conclusaode-bolsistas/trabalhos-de-conclusao-de-bolsistas-a-partir-de-2018/ciencias-dasaude/especializacao-2/646-contribuicoes-e-desafios-do-profissional-psicologofrente-ao-cuidado-e-protecao-de-mulheres-vitimas-de-violencia/file. Acesso em: 07 nov. 2020.

WAISELFISZ, Julio Jacobo. Mapa da violência 2015: homicídio de mulheres no Brasil. Brasília: Flacso, 2015. 
Relatório gerado por: mayannehollerbach@outlook.com

\section{Arquivos}

Termos comuns Similaridade

TCC.docx X

https://www.politize.com.br/violencia-domestica-no-brasil

188

TCC.docx X

203

http://www.scielo.br/scielo.php?script=sci_arttext\&pid=S0102-

311X2016000400704

TCC.docx X

https://covid19.appcode.com.br

TCC.docx X

https://www.faculdadealfa.com.br

TCC.docx X

https://www.missionaustralia.com.au/what-we-do/children-

youth-families-and-communities/domestic-family-violence

TCC.docx X

https://www25.senado.leg.br/web/atividade

TCC.docx X

https://www2.senado.leg.br

TCC.docx X

http://www.teofilootoni.mg.gov.br/wp-

content/uploads/2020/04/Classificação-ACS-24-2020.pdf

TCC.docx X

https://www25.senado.leg.br/web/senadores/em-exercicio

TCC.docx X

https://www.gov.br/planalto/pt-br

$5 \quad 0,09$

5

0,08

5

0,08 
Arividade: Trabalho de Conclusaso de Curso - Artigo

Curso: Psicologia Periodo: $10^{\circ} \quad$ Semestre: $2^{\circ} \quad$ Ano: 2020

Professor (a): Isabel Correa Pacheco

Acadômico: Mayanme flollerbach Amaral

Tema: A importancia da atuacä́o do priélogo nas casos emroluendo violéncia doméstica e

Assinatura do aluno Lamiliar cancra a nomerier

Data(s) do(s) atendimento(s)

$2 0 1 0 8 \longdiv { 2 0 2 0 }$

$3 4 / 0 9 \longdiv { 2 0 2 0 }$

Jo $/ 10 / 2020$

$11111 / 2020$

$1 2 1 1 1 \longdiv { 2 0 2 0 }$

Horário(s)
$\frac{12: 00}{16: 00}$
$\frac{10: 00}{09: 00}$
$08: 00$

$08: 00$

Descrição das orientaçôes:

Discussáo do projeto preliminar

Avaliaçáo da fundamentação teórica

Discussáo $\theta$ adequação da metodologia

Orientaçăo referente a discussăo

Avaliaçẩo da apresentaçăo gráfica

Considerando a concordancia com o trabalho realizado sob minha orientaçăo, AUTORIzO O DEPósito do Trabalho de Conclusăo de curso do (a) Acadêmico (a) Mayanne Hollerbach Amaral 
Atividade: Trabalho de Conclusâo de Curso - Artigo

Curso: Psicologia Poriodo: $10^{\circ} \quad$ Semestre: $2^{\circ} \quad$ Ano: 2020

Professor (a): Isabel Corrêa Pacheco

Acadêmico: Dhaiamy Olivtina Comangos

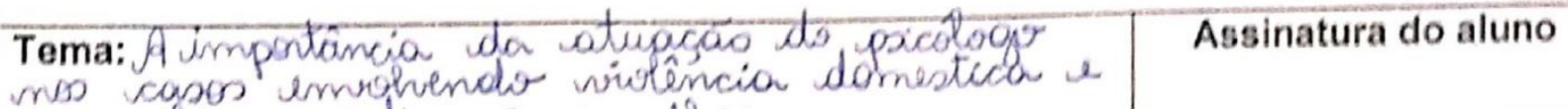

Data(s) do(s) atendimento(s) $\quad$ Horário(s)

$20108 / 2020$

$14109 / 2020$

$10 / 10 / 20,20$

$11 / 11 / 2020$

$12111 / 2020$ $2: 00$

Descrição das orientações:

Discussäo do projeto preliminar

Avaliação da fundamentação teórica

Discussão e adequação da metodologia

Orientaçăo referente à discussão

Avaliação da apresentaçăo gráfica

Considerando a concordância com o trabalho realizado sob minha orientaçăo, AUTORIZO O DEPÓsITo do Trabalho de Conclusão de Curso do (a) Acadêmico (a) Dhaiamy Olitio camargo

Assinatura do Professor

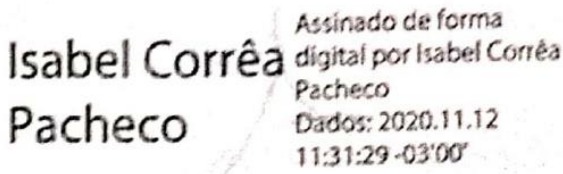

